\title{
A Study of Seasonal Variation in the Effect of Add-On Sitagliptin on Blood Glucose Control in Insulin-Treated Patients With Type 2 Diabetes
}

\author{
Masahiko Takai ${ }^{a}$, Masashi Ishikawa ${ }^{a}$, Hajime Maeda ${ }^{a}$, Akira Kubota ${ }^{a}$, Kotaro Iemitsu ${ }^{a}$, \\ Shinichi Umezawa ${ }^{\text {a }}$, Takehiro Kawata ${ }^{a}$, Tetsuo Takuma ${ }^{\text {a }}$, Hiroshi Takeda ${ }^{\text {a }}$, \\ Keiji Tanaka ${ }^{\text {a }}$ Hideo Machimura ${ }^{a}$, Fuyuki Minagawa ${ }^{a}$, Atsuko Mokubo ${ }^{\text {, }}$ \\ Tetsuya Motomiya ${ }^{\mathrm{a}}$, Akira Kanamoria ${ }^{\mathrm{a}}$, Ikuro Matsuba ${ }^{\mathrm{a}, \mathrm{b}}$
}

\begin{abstract}
Background: There are several reports of seasonal variation in hemoglobin A1c (HbA1c) in patients with type 2 diabetes (T2DM), but no reports of seasonal variation in the effect of add-on drugs on blood glucose control in insulin-treated patients.
\end{abstract}

Methods: Using data collected from 630 patients in a multicenter study, we compared the amount of change in HbAlc after 1, 3, 6, 9 , and 12 months of add-on administration of sitagliptin in insulintreated patients divided into four groups based on the month when sitagliptin was started.

Results: A significantly larger decrease in $\mathrm{HbA} 1 \mathrm{c}$ at 6 months from baseline was observed in the group that started add-on sitagliptin in February to April than in the other three groups. However, the amount of change in $\mathrm{HbA} 1 \mathrm{c}$ at 12 months did not differ among the groups.

Conclusions: The consideration of seasonal variation enables more accurate evaluation of a drug's short-term effect on blood glucose control.

Keywords: Sitagliptin; Seasonal effect; Dipeptidyl peptidase-4 inhibitor; HbA1c; Type 2 diabetes

\section{Introduction}

Seasonal variation in hemoglobin A1c (HbA1c) level in pa-

\section{Manuscript submitted January 29, 2020, accepted February 21, 2020}

aDiabetes Committee Study Group, Kanagawa Physicians Association, 1-3 Fujimichou, Nakaku, Yokohama, Kanagawa 231-0037, Japan

bCorresponding Author: Ikuro Matsuba, Kanagawa Diabetes Task Force, Kanagawa Physicians Association, 1-3 Fujimichou, Nakaku, Yokohama, Kanagawa 231-0037, Japan. Email: ikuro@matsuba-web.com

doi: https://doi.org/10.14740/jocmr4103 tients with type 2 diabetes (T2DM) has been reported [19]. The most frequently reported month in which $\mathrm{HbA1c}$ reached its highest level was March in Japan $[1,2,4]$ and January to March in other countries in the Northern Hemisphere [1-6]. Although periods in which HbAlc fell to its lowest level varied slightly, they were generally reported to be August to October in the Northern Hemisphere [1-6]. Fleegler et al have reported that the pattern of variation in the incidence of diabetes by month in cities in the Northern Hemisphere was the reverse of that in cities in the Southern Hemisphere [10]. A correlation between HbA1c levels and mean temperatures has also been reported [1]. To treat patients with T2DM, it is important to lower blood glucose levels and keep them constant. Seasonal variation can interfere with blood glucose control in diabetic patients. However, a report by Sakura et al is the only study that verified seasonal variation in the effect of antidiabetic drugs throughout the year [7], and there has been no study that verified seasonal variation in the effect of antidiabetic drugs used concomitantly with insulin.

Therefore, we used data collected in the multicenter ASSIST-K study [11-14] to verify seasonal variation in the effect of add-on sitagliptin on blood glucose control in patients on insulin therapy.

\section{Materials and Methods}

\section{Study design}

The ASSIST-K study was a 1-year multicenter retrospective observational study conducted at member institutions of the Kanagawa Physicians Association that specialized in managing diabetes. This study was approved by the Ethics Review Board of the Kanagawa Physicians Association. This study was registered with the Clinical Trials Registry (http://clinicaltrials.gov; NCT01855087) and was undertaken in accordance with the study protocol, the Declaration of Helsinki and the Ethical Guidelines for Clinical Studies of the Japanese Ministry of Health, Labour, and Welfare. Informed consent 
was not required because of the retrospective character of the study.

\section{Subjects}

This retrospective study included patients receiving sitagliptin in addition to insulin from November 2011 to March 2013 at 36 diabetes clinics in Kanagawa Prefecture, Japan. Outpatients with T2DM over 20 years old attending member institutions of the Kanagawa Physicians Association were eligible to be enrolled in this study if they had shown poor glycemic control on insulin therapy for at least 1 month before the initiation of sitagliptin. The following patients were excluded: patients with a history of hypersensitivity to any of the ingredients of sitagliptin; patients who had experienced severe ketoacidosis, diabetic coma, or precoma within 6 months before starting sitagliptin; patients with severe infection; patients in the preoperative or postoperative period; patients with severe trauma; patients using glinides; and other patients who were judged to be inappropriate for this study by the investigator.

Among patients enrolled in the ASSIST-K study, those receiving sitagliptin as add-on therapy to insulin were analyzed if they had HbAlc data at both the start and after 12 months of sitagliptin treatment (i.e. the population in which the change in $\mathrm{HbAlc}$ over 12 months could be calculated). In addition, in order to accurately verify the relationship between the blood glucose control effect of sitagliptin and seasonal variations, the following patients were excluded: patients whose HbAlc was less than $6.9 \%$; patients with inadequate medication information; and patients who had switched drugs at the start of sitagliptin administration.

\section{Endpoints}

Demographic factors were investigated, including the sex, age, body mass index (BMI), duration of diabetes, and medical complications. To investigate the seasonal effect of sitagliptin on the reduction of $\mathrm{HbAlc}$, patients were divided into four groups based on the month when sitagliptin was started.

$\mathrm{HbAlc}$ was most frequently reported to reach its highest level in March in Japan [1, 2, 4] and its lowest level in August to October [1-4]. Therefore, patients were divided into four groups based on the period in which sitagliptin was started: group 1 (in February to April), group 2 (in May to July), group 3 (in August to October), and group 4 (in November to January of the following year), which is the same as previously described [7]. Then changes in HbA1c and BMI at 1, 3, 6, 9, and 12 months from baseline, which was the first day of sitagliptin administration, were compared within each group and among the groups. Moreover, the amount of change in $\mathrm{HbAlc}$ at 6 months from baseline was also analyzed after adjustment for patients' characteristics. The occurrence of hypoglycemia was also analyzed by the period when sitagliptin was started. The definition of hypoglycemia in this study was "patients with subjective symptoms and reported as hypoglycemia by a physician as an adverse event".

\section{Statistical analysis}

The data were analyzed using $\mathrm{R}$ version 3.5.2 ( $\mathrm{R}$ Foundation for Statistical Computing, Vienna, Austria (https://www.Rproject.org/)). To test for differences in patient characteristics, we used analysis of variance (ANOVA) for continuous variables and the Chi-squared test for nominal variables. For intragroup changes in $\mathrm{HbA} 1 \mathrm{c}$ and $\mathrm{BMI}$, changes from baseline were compared using the paired $t$-test. In these comparisons, multiplicity was not considered. For the intergroup comparison of HbA1c and BMI, the Tukey-Kramer test was used. We also considered the possibility that other patient characteristics may have influenced the amount of change in HbA1c and performed an analysis of covariance with amount of change in $\mathrm{HbA} 1 \mathrm{c}$ at 6 months from baseline as the objective variable, group (or period when sitagliptin was started) as the fixed factor, and $\mathrm{HbA} 1 \mathrm{c}$ and BMI at the start of sitagliptin, sex, age, amount of change in BMI at 6 months from baseline, the number of insulin administrations per day, the amount of insulin administered per day, the use of long-acting insulin, the change in the amount of insulin administered per day at 6 months from baseline, and the concomitant use of sulfonylureas (SU) as covariates. Regarding the occurrence of hypoglycemia, differences in the number of patients who developed hypoglycemia at 0 (baseline) to 3 months, 4 to 6 months, 7 to 9 months, and 10 to 12 months were analyzed using the Chi-squared test. Significance was set to a two-sided $\mathrm{P}$ value of $<0.05$. Nominal data are presented as the number of cases (\%) and continuous data as mean \pm standard deviation.

\section{Results}

Of 1,168 patients enrolled in the ASSIST-K study at 36 institutions in Kanagawa Prefecture, 630 patients met the present study's criteria and were considered analyzable (Fig. 1). Characteristics of the patients in each group are shown in Table 1. There were 172, 113, 151, and 194 patients in groups 1, 2, 3, and 4 , respectively. Intergroup differences were observed in age, the concomitant use of SU, BMI, diastolic blood pressure, high-density lipoprotein cholesterol, and blood urea nitrogen.

Change in HbA1c in each group is shown in Figure 2, and the amount of change in each group is shown in Figure 3. Regarding intragroup changes from baseline, significant decreases were observed at all timepoints from 1 month to 12 months from baseline. There was no significant intergroup difference in $\mathrm{HbA1c}$ at baseline, while the largest decrease in HbAlc at 6 months from baseline was observed in group 1 (group 1: -1.04 \pm 1.13 , group 2: $-0.70 \pm 0.98$, group $3:-0.63 \pm 1.06$, and group 4: $-0.71 \pm 1.06$; group 1 vs. group $2: \mathrm{P}=0.045$, group $1 \mathrm{vs.}$ group 3: $\mathrm{P}=0.005$, and group 1 vs. group $4: \mathrm{P}=0.021)$. Regarding the amount of change in $\mathrm{HbAl}$ c at 3 months, a significant difference was observed between groups 1 and 4 (group 1: $-0.88 \pm 1.03$ and group 4: $-0.56 \pm 1.00$; group 1 vs. group $4: \mathrm{P}=$ 0.010 ), while there was no intergroup difference in the amount of change in HbAlc at 1, 9, or 12 months.

The amount of change in BMI from baseline showed a 


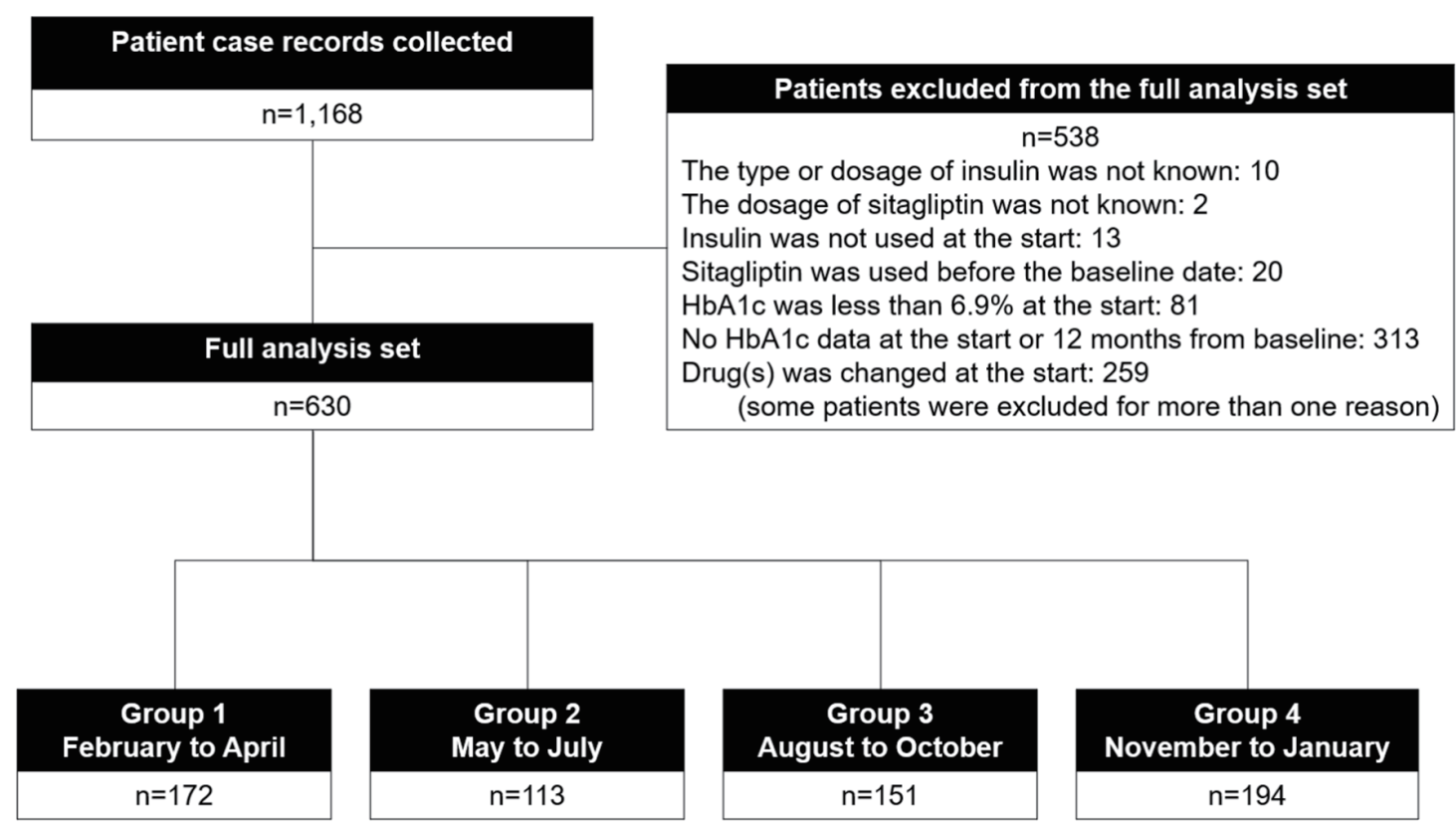

Figure 1. Participant flow.

significant difference only at 1 month between groups 2 and 3 (group 2: $-0.01 \pm 0.41$, and group 3: $0.15 \pm 0.49, \mathrm{P}=0.037$ ). No significant intergroup difference was observed at any other timepoint (Supplementary Material 1, www.jocmr.org). We conducted an analysis of covariance of the amount of change in $\mathrm{HbA} 1 \mathrm{c}$ at 6 months from baseline, which took into account the influences of $\mathrm{HbA} 1 \mathrm{c}$ and BMI at the start of sitagliptin, sex, age, the amount of change in BMI at 6 months from baseline, the number of insulin administrations per day, the amount of insulin per day, the use of long-acting insulin, the amount of change in insulin administered per day at 6 months from baseline, and the concomitant use of SU. This analysis showed a significantly larger decrease in group 1 than in any of the other three groups (Fig. 4).

There was no significant intergroup difference in the period of hypoglycemia occurrence (Table 2).

\section{Discussion}

Regarding the effect of add-on sitagliptin on blood glucose control in insulin-treated patients, the results of the present study showed that the decrease in HbAlc at 6 months from baseline was significantly larger in the February-to-April group (group 1; the group in which sitagliptin was started in February to April) than in the other three groups. However, decrease in HbAlc at 12 months from baseline was not significantly larger among the groups. Even after adjusting for patient characteristics, the analysis of covariance of factors influencing the amount of change in $\mathrm{HbA} 1 \mathrm{c}$ at 6 months from baseline showed a significantly larger decrease in group 1 than in the other groups. No reports have disclosed a seasonal difference in the effect of antidiabetic drugs used concomitantly with insulin, and therefore these findings should be regarded as new real-world evidence of that difference.

Sakura et al have reported on seasonal variation in the effect of sitagliptin in patients who were not using insulin concomitantly [7]. The present study followed their scheme for grouping patients. In their report, the HbAlc-lowering effect at 3 months from baseline was smaller in group 3, whose patients started sitagliptin in August to October, than in the other groups. In our study, the decrease in $\mathrm{HbAlc}$ at 3 months from baseline was significantly larger in group 1, whose patients started sitagliptin in February to April, than in group 4, whose patients started sitagliptin in November to January. No other significant intergroup difference was observed. Although their results and our results cannot be strictly compared because Sakura et al did not measure the HbA1c-lowering effect at 6 months from baseline, what these results have in common is that they show the effect of sitagliptin is seasonally dependent. Our findings indicate that when sitagliptin is started in the high HbA1c period, a larger decrease in HbAlc is observed at 6 months from baseline than in other groups. By contrast, the report by Sakura et al indicates that when sitagliptin is started in the low HbAlc period, HbAlc is less likely to decrease than in other periods. The temporal difference in these seasonal variations may be due to the higher HbAlc level at the start of sitagliptin in group 3 in August to October in our study $(8.70 \pm 1.31)$ than in the study by Sakura et al $(7.75 \pm$ $0.97)$. Since the subjects in our study were using insulin concomitantly, they had high baseline levels. Although HbA1c levels showed no significant intergroup difference at the start of sitagliptin, they were slightly higher in group 3 than in groups 1 and 2 . In the report by Sakura et al, HbA1c levels also showed no intergroup difference at the start of sitagliptin and were slightly lower in group 3 than in groups 1, 2, and 4 . Baseline HbA1c levels in the report by Sakura et al were high in group 1 and low in group 3, which is similar to many of 


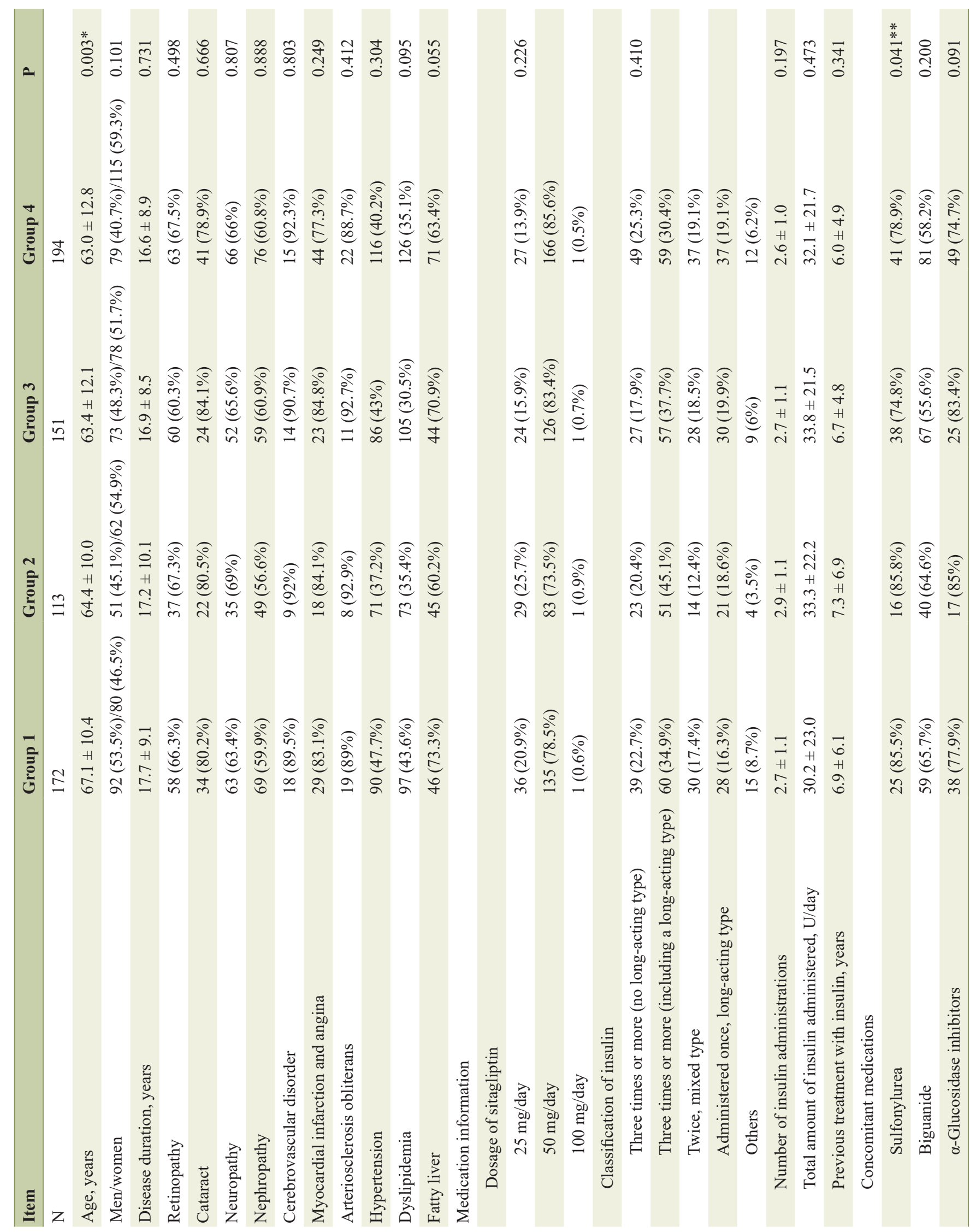




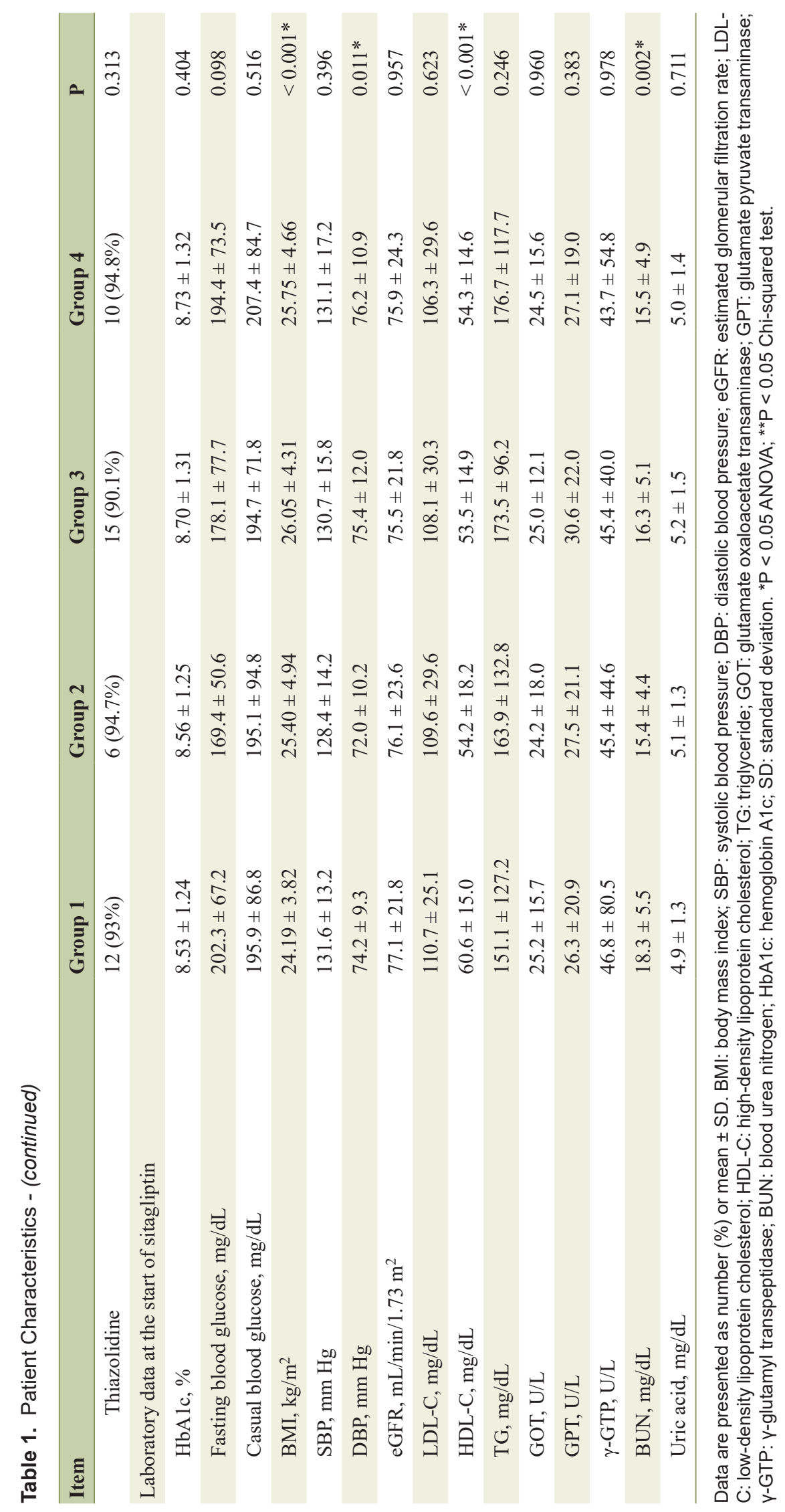




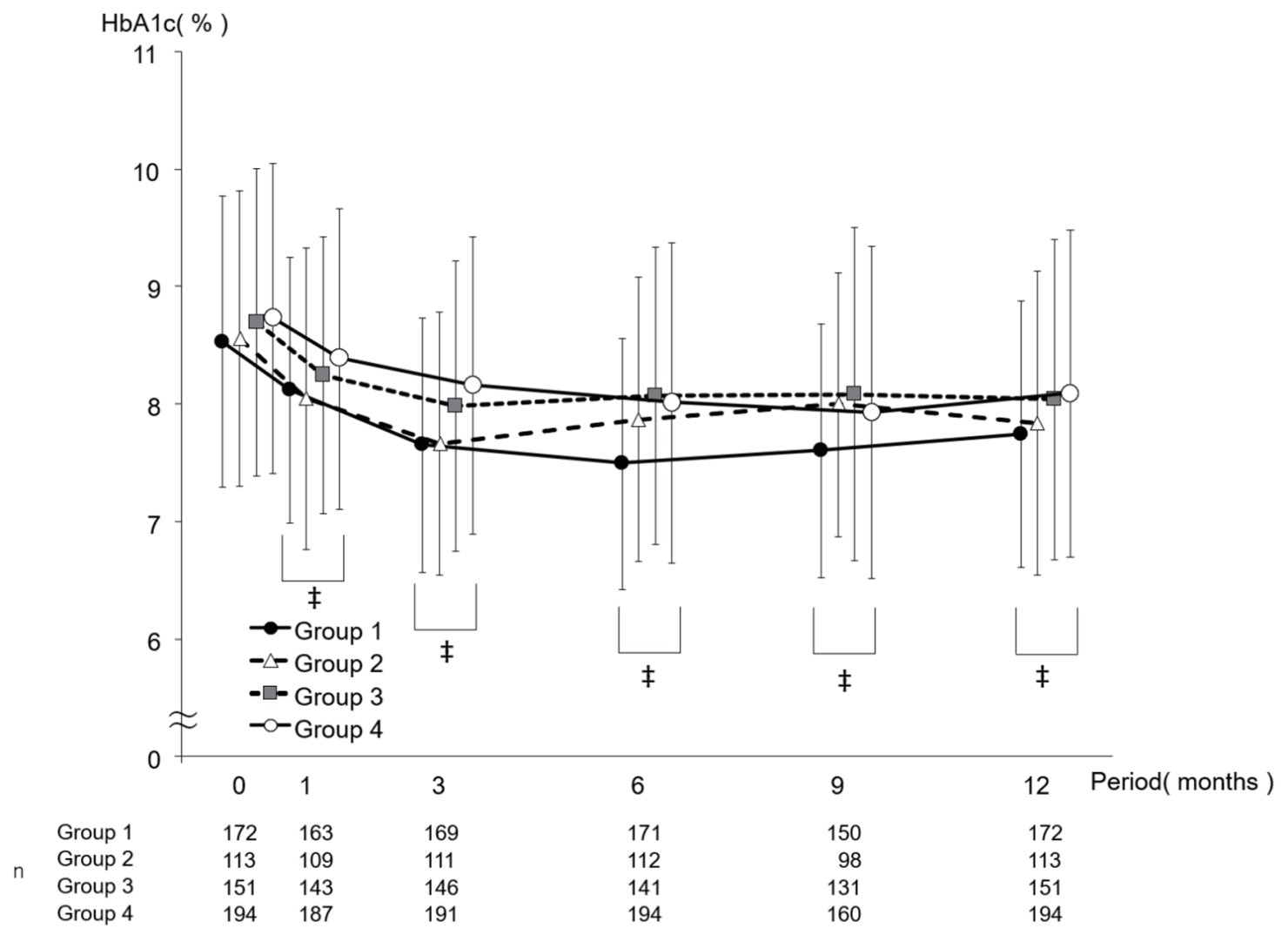

Figure 2. Change in $\mathrm{HbA} 1 \mathrm{c}$ by period in which sitagliptin was started. Data are presented as mean \pm standard deviation. $\ddagger \mathrm{P}<$ 0.05 versus 0 months paired $t$-test. HbA1c: hemoglobin A1c.

the previous papers reporting seasonal variation but different from our report. In our report, baseline $\mathrm{HbA} 1 \mathrm{c}$ levels in group 3 were conceivably high enough to decrease sufficiently at 3 months from baseline. We think that this factor also contributed to differences observed in the timepoint when intergroup differences were detected by analysis based on the period of sitagliptin initiation.

Regarding eating habits in winter, changes are likely to occur during Christmas, the year-end, and New Year holidays. Jones et al have reported that blood glucose and lipids levels were higher in the 31 days after Christmas than their annual averages [15]. Gikas et al have also reported that fasting blood glucose levels reached a clear peak after Christmas [16]. Although changes in eating habits during Christmas, year-end, and New Year holidays are short-term [15], irregular eating habits can continue after these holidays, and therefore we should be cognizant of their influences on blood glucose levels and $\mathrm{HbAlc}$.

Kanamori et al have reported noncompliance with diet/exercise therapy in a group with increasing HbAlc levels in early winter even after sitagliptin initiation, and in contrast to a group with stabilized HbAlc levels after sitagliptin initiation [17]. Although we have no data on compliance with diet and exercise therapies at 6 months from baseline in the present study, a relative lack of exercise in the winter compared with summer could be a factor contributing to the increase in $\mathrm{HbAlc}$.
This report by Kanamori et al also compared changes in $\mathrm{BMI}$ and found no seasonal difference. Sohmiya et al also have reported that body fat and $\mathrm{HbA} 1 \mathrm{c}$ levels increased in winter and decreased in summer, while body weight did not change markedly [3]. In our study, although the amount of change in BMI at 6 months from baseline did not differ significantly among the groups based on when sitagliptin was started, only BMI in group 1 tended to decrease. In the analysis of covariance of factors affecting the amount of change in HbAlc level at 6 months from baseline, however, the period when sitagliptin was started was a significant factor, even when the influence of change in BMI was accounted for by including it as a covariate. The present report also supported the notion that seasonal change in $\mathrm{HbA} 1 \mathrm{c}$ level is not necessarily the same as seasonal change in body weight.

Hypoglycemia was analyzed by sitagliptin initiation period. No seasonal difference was detected. Hashimoto et al have reported that more patients were hospitalized due to hypoglycemia during the cold season. However, when only insulintreated patients were analyzed, no significant seasonal difference was detected [18]. In the present study, all patients used insulin. The absence of a seasonal difference in the incidence of hypoglycemia may be because insulin dosage can be easily adjusted through physician-patient communication. In a different study in Japan, severe antidiabetic drug-induced hypoglycemia occurred more frequently in the cold season than in the 


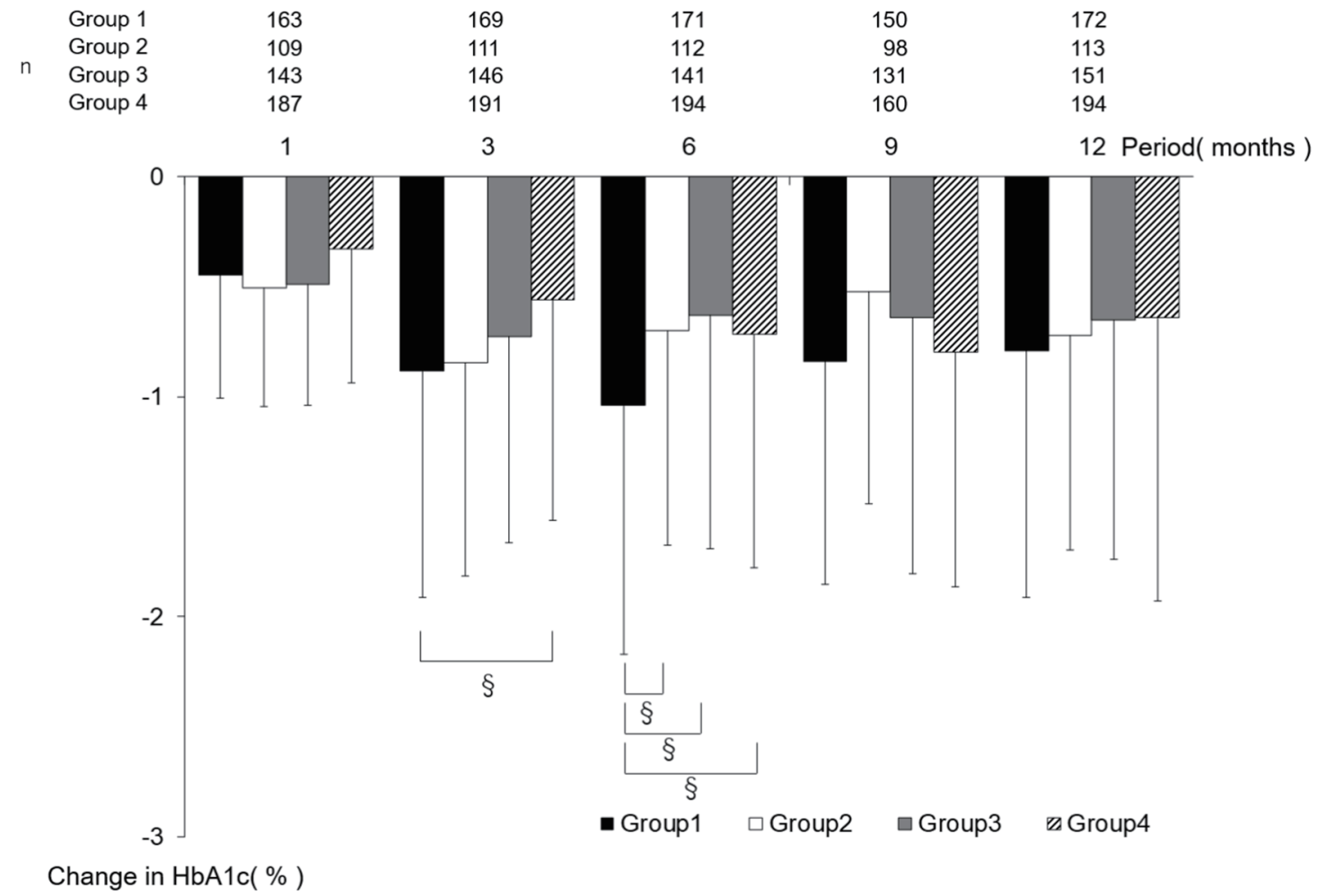

Figure 3. The amount of change in $\mathrm{HbA} 1 \mathrm{c}$ by the period in which sitagliptin was started. Data are presented as mean \pm standard deviation. $\S \mathrm{P}<0.05$ Tukey-Kramer test. HbA1c: hemoglobin A1c.

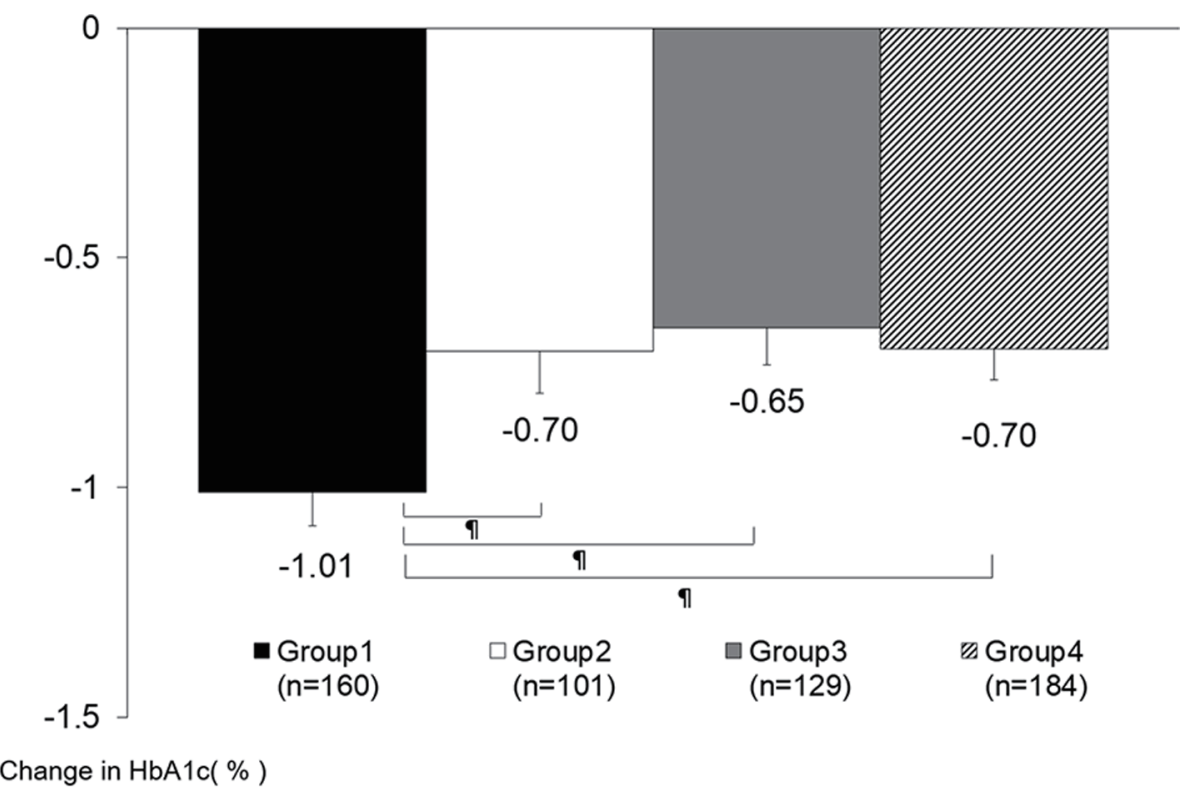

Figure 4. The amount of change in $\mathrm{HbA} 1 \mathrm{c}$ at 6 months from baseline (analysis of covariance). Data are presented as least squares mean \pm standard error. $\mathbb{P}<<0.05$ ANCOVA. Groups 1 versus $2: P=0.009$, groups 1 versus $3: P=0.001$, groups 1 versus 4: $P=0.002$, groups 2 versus 3: $P=0.677$, groups 2 versus $4: P=0.965$, groups 3 versus $4: P=0.662$. Covariates: HbA1c and BMI at baseline, sex, age, the amount of change in BMI at 6 months from baseline, the number of insulin administrations per day, the amount of insulin per day, the use of long-acting insulin, the change in the amount of insulin administered per day at 6 months from baseline, and the concomitant use of sulfonylureas. HbA1c: hemoglobin A1c; ANCOVA: analysis of covariance; BMI: body mass index. 
Table 2. Number of Patients Who Developed Hypoglycemia

\begin{tabular}{lllllll} 
& n & $\mathbf{0 ~ - ~ 3 ~ m o n t h s ~}$ & $\mathbf{4 - 6}$ months & $\mathbf{7 - 9}$ months & $\mathbf{1 0}$ - 12 months & By 12 months from baseline \\
\hline Group 1 & 172 & $17(9.9 \%)$ & $8(4.7 \%)$ & $9(5.2 \%)$ & $8(4.7 \%)$ & $25(14.5 \%)$ \\
Group 2 & 113 & $10(8.8 \%)$ & $5(4.4 \%)$ & $6(5.3 \%)$ & $4(3.5 \%)$ & $16(14.2 \%)$ \\
Group 3 & 151 & $4(2.6 \%)$ & $0(0 \%)$ & $3(2.0 \%)$ & $6(4.0 \%)$ & $12(7.9 \%)$ \\
Group 4 & 194 & $13(6.7 \%)$ & $10(5.2 \%)$ & $8(4.1 \%)$ & $11(5.7 \%)$ & $23(11.9 \%)$ \\
P & & 0.094 & 0.054 & 0.444 & 0.818 & 0.275 \\
\hline
\end{tabular}

Data are $n(\%)$. N.S. Chi-squared test. N.S.: no significance.

warm season and was associated with inflammation in patients treated with SU [19]. In this study, the data of 125 severe cases were collected over 14 years since 2001, which is longer than the period of data collection in our study. Moreover, since the effect of sitagliptin depends on blood glucose level, hypoglycemia is conceivably less likely to occur. The insulin secretagogue action of glucagon-like peptide 1 depends on blood glucose level [20]. A meta-analysis of the effects of dipeptidyl peptidase-4 (DPP-4) inhibitors demonstrated that they are associated with a lower risk of inducing hypoglycemia than SU [21]. Since many studies have reported the improbability that sitagliptin induces hypoglycemia [22-25], a small number of hypoglycemic events that occurred is conceivably one of the factors contributing to the absence of seasonal difference in the occurrence of hypoglycemic events.

The exact mechanism of the seasonal change in this study is unknown. However, we believe that not only does $\mathrm{HbAlc}$ negatively correlates with temperature, but also the properties of DPP-4 inhibitors that exert their effects in a blood glucosedependent manner. For this reason, we consider that other DPP-4 inhibitors have seasonal variations in the effect, similar to the present results. There is no paper that mentions seasonal variation when using other diabetes medications, so we cannot say for sure. However, if other diabetes medications have seasonal effect, it may only have small difference compared to this study. Further investigation is desired about it.

The present study has several limitations. First, it was retrospective in design with data collected from patients on insulin therapy who were able to continue sitagliptin concomitantly at least for a certain period of time, and thus it was susceptible to patient selection bias. Second, there was no control group. Third, the analysis did not include drinking and smoking information due to the large amount of unknown data. Fourth, dosages of insulin or antidiabetic drugs were not fixed. At last, the seasonal effect of a drug on blood glucose control was not observed for all drugs.

\section{Conclusions}

The decrease in HbAlc at 6 months from the start of sitagliptin was significantly larger in insulin-treated patients who started sitagliptin in February to April than in those who started it in other periods. However, the amount of change in HbAlc at 12 months is similar among the sitagliptin initiation periods. The consideration of seasonal variation enables more accurate evaluation of the short-term effect of a drug on blood glucose control.

\section{Supplementary Material}

Suppl 1. The Change in BMI by the Period in Which Sitagliptin Was Started.

\section{Acknowledgments}

The authors would like to thank the members of the Kanagawa Physicians Association.

\section{Financial Disclosure}

This research was financially supported by the Kidney Foundation, Japan.

\section{Conflict of Interest}

The authors declare no conflict of interest.

\section{Informed Consent}

Informed consent was not required because of the retrospective character of the study.

\section{Author Contributions}

MT, MI and IM conceived and designed the experiments; MT, MI, HM, AK, KI, SU, TK, TT, HT, KT, HM, FM, AM, TM, AK, and IM enrolled patients; IM analyzed the data; MT wrote the first draft of the manuscript; MI and IM contributed to the writing of the manuscript. All authors agreed with the manuscript's results and conclusions, and all authors have read ICMJE criteria and confirm that they meet ICMJE criteria for authorship.

\section{Data Availability}

The biochemical data used to support the findings of this study are available from the corresponding author upon request. 


\section{References}

1. Sakura H, Tanaka Y, Iwamoto Y. Seasonal fluctuations of glycated hemoglobin levels in Japanese diabetic patients. Diabetes Res Clin Pract. 2010;88(1):65-70.

2. Iwao T, Sakai K, Ando E. Seasonal fluctuations of glycated hemoglobin levels in Japanese diabetic patients: effect of diet and physical activity. Diabetol Int. 2013;4:173178.

3. Sohmiya M, Kanazawa I, Kato Y. Seasonal changes in body composition and blood HbAlc levels without weight change in male patients with type 2 diabetes treated with insulin. Diabetes Care. 2004;27(5):1238-1239.

4. Ishii H, Suzuki H, Baba T, Nakamura K, Watanabe T. Seasonal variation of glycemic control in type 2 diabetic patients. Diabetes Care. 2001;24(8):1503.

5. Pereira MT, Lira D, Bacelar C, Oliveira JC, de Carvalho AC. Seasonal variation of haemoglobin A1c in a Portuguese adult population. Arch Endocrinol Metab. 2015;59(3):231-235.

6. Kim YJ, Park S, Yi W, Yu KS, Kim TH, Oh TJ, Choi J, et al. Seasonal variation in hemoglobin alc in korean patients with type 2 diabetes mellitus. J Korean Med Sci. 2014;29(4):550-555.

7. Sakura H, Hashimoto N, Sasamoto K, Ohashi H, Hasumi S, Ujihara N, Kasahara T, et al. Analysis of the effect of seasonal administration on the efficacy of sitagliptin: subanalysis of the Januvia multicenter prospective trial in type 2 diabetes study. J Diabetes Investig. 2018;9(5):11591166.

8. Iwata K, Iwasa M, Nakatani T, Yano Y, Mifuji-Moroka R, Hara N, Akamatsu M, et al. Seasonal variation in visceral fat and blood HbA1c in people with type 2 diabetes. Diabetes Res Clin Pract. 2012;96(3):e53-54.

9. Zhang L, Li W, Xian T, Pan Q, Li M, Guo L. Seasonal variations of hemoglobin A1c in residents of Beijing, China. Int Clin Exp Pathol. 2016;9:9429-9435.

10. Fleegler FM, Rogers KD, Drash A, Rosenbloom AL, Travis LB, Court JM. Age, sex, and season of onset of juvenile diabetes in different geographic areas. Pediatrics. 1979;63(3):374-379.

11. Takai M, Ishikawa M, Maeda H, Kanamori A, Kubota A, Amemiya H, Iizuka T, et al. Safety and efficacy of adding sitagliptin to insulin in patients with type 2 diabetes: the ASSIST-K study. Diabetes Res Clin Pract. 2014;103(3):e30-33.

12. Ishikawa M, Takai M, Maeda H, Kanamori A, Kubota A, Amemiya H, Iizuka T, et al. Factors predicting therapeutic efficacy of combination treatment with sitagliptin and insulin in type 2 diabetic patients: the ASSIST-K study. J Clin Med Res. 2015;7(8):607-612.

13. Takai M, Ishikawa M, Maeda H, Kanamori A, Kubota A, Amemiya H, Iizuka T, et al. Efficacy and safety of adding sitagliptin in type 2 diabetes patients on insulin: agestratified comparison at one year in the ASSIST-K study. J Clin Med Res. 2019;11(5):311-320.

14. Ishikawa M, Takai M, Maeda H, Kanamori A, Kubota A,
Amemiya H, Iizuka T, et al. Add-on sitagliptin therapy for insulin-treated type 2 diabetes: an analysis of hemoglobin A1c and other variables using ASSIST-K follow-up data. J Endocrinol Metab. 2018;8(6):126-138.

15. Jones AG, McDonald TJ, Hattersley AT, Shields BM. Effect of the holiday season in patients with diabetes: glycemia and lipids increase postholiday, but the effect is small and transient. Diabetes Care. 2014;37(5):e98-99.

16. Gikas A, Sotiropoulos A, Pastromas V, Papazafiropoulou A, Apostolou O, Pappas S. Seasonal variation in fasting glucose and $\mathrm{HbA} 1 \mathrm{c}$ in patients with type 2 diabetes. Prim Care Diabetes. 2009;3(2):111-114.

17. Kanamori A, Matsuba I. Factors associated with reduced efficacy of sitagliptin therapy: analysis of 93 patients with type 2 diabetes treated for 1.5 years or longer. J Clin Med Res. 2013;5(3):217-221.

18. Hashimoto T, Morita A, Hashimoto Y, Yagami F, Sakamoto K, Owada M, Sugawara T, et al. Seasonal variation of severe hypoglycemia in hospitalized patients 60 years of age or older presenting to an emergency center hospital between 2004 and 2010. Intern Med. 2013;52(24):27212726.

19. Minamoto-Higashioka M, Kawamura R, Umakoshi H, Yokomoto-Umakoshi M, Utsunomiya D, Osawa H, Kondo S. Seasonal variation in severe glucose-lowering druginduced hypoglycemia in patients with type 2 diabetes. Intern Med. 2019;58(8):1067-1072.

20. Nauck MA, Heimesaat MM, Behle K, Holst JJ, Nauck MS, Ritzel R, Hufner M, et al. Effects of glucagon-like peptide 1 on counterregulatory hormone responses, cognitive functions, and insulin secretion during hyperinsulinemic, stepped hypoglycemic clamp experiments in healthy volunteers. J Clin Endocrinol Metab. 2002;87(3):12391246.

21. Monami M, Iacomelli I, Marchionni N, Mannucci E. Dipeptydil peptidase- 4 inhibitors in type 2 diabetes: a metaanalysis of randomized clinical trials. Nutr Metab Cardiovasc Dis. 2010;20(4):224-235.

22. Maeda H, Kubota A, Tanaka Y, Terauchi Y, Matsuba I, ASSET-K Study group. The safety, efficacy and predictors for $\mathrm{HbAlc}$ reduction of sitagliptin in the treatment of Japanese type 2 diabetes. Diabetes Res Clin Pract. 2012;95(1):e20-22.

23. Yuasa S, Sato K, Takai M, Ishikawa M, Umezawa S, Kubota A, Maeda H, et al. Factor analysis of changes in Hemoglobin A1c after 12 months of sitagliptin therapy in patients with type 2 diabetes. J Clin Med Res. 2016;8(6):461-471.

24. Iwamoto Y, Tajima N, Kadowaki T, Nonaka K, Taniguchi T, Nishii M, Arjona Ferreira JC, et al. Efficacy and safety of sitagliptin monotherapy compared with voglibose in Japanese patients with type 2 diabetes: a randomized, double-blind trial. Diabetes Obes Metab. 2010;12(7):613622.

25. Green JB, Bethel MA, Armstrong PW, Buse JB, Engel SS, Garg J, Josse R, et al. Effect of sitagliptin on cardiovascular outcomes in type 2 diabetes. N Engl J Med. 2015;373(3):232-242. 